\title{
10 \\ REKONSTRUKSI PERAN PUSTAKAWAN DI ERA GLOBALISASI
}

\author{
Aat Hidayat \\ STAIN Kudus, Jawa Tengah, Indonesia \\ aathiedayat@gmail.com
}

\begin{abstract}
RECONSTRUCTION LIBRARIAN ROLE IN GLOBALIZATION ERA. Talking about the increase in human resources, substantively library occupies a very urgent role. However, more library serves as a storage pile of books deserted from literacy activities, let alone research and development activities. This article examines how should the role of librarians in globalization era. In this globalization era, there are four important role librarians, that is collecting and providing access to information and knowledge and sources scattered around the world in multiformat, add or put a value on information and knowledge (adding value), provides online service for 24 hours, and provide varied and dynamic services, included the whole cycle of knowledge, from creation, recording and publication, dissemination, use, and re-creation of knowledge. With these four librarians role, expected to libraries in globalization era not merely as "noun", that is a place to store a collection of books and a variety of other collections, but the library is able to transform a "verb" or process, that is nursery places and dissemination of knowledge.
\end{abstract}

Keywords: Librarian, Globalization, Digital Library, Digital Natives. 


\begin{abstract}
Abstrak
REKONSTRUKSI PERAN PUSTAKAWAN DI ERA GLOBALISASI. Berbicara mengenai peningkatan sumber daya manusia, sejatinya perpustakaan menempati peran yang sangat urgen. Namun, perpustakaan lebih banyak berfungsi sebagai tempat penyimpanan tumpukan buku-buku yang sepi dari kegiatan literasi, apalagi aktivitas penelitian dan pengembangan. Artikel ini menelaah bagaimana sebaiknya peran pustakawan di era globalisasi saat ini. Di era globalisasi ini, ada empat peran penting pustakawan, yaitu mengoleksi dan menyediakan akses ke informasi dan pengetahuan serta sumber-sumbernya yang tersebar di seluruh dunia dalam multiformat, menambah atau memberikan nilai pada informasi dan pengetahuan (adding value), memberikan pelayanan online selama 24 jam, dan memberikan pelayanan bervariasi dan dinamis, meliputi seluruh siklus pengetahuan, mulai dari penciptaan, perekaman dan publikasi, penyebaran, penggunaan, dan penciptaan kembali pengetahuan. Dengan empat peran pustakawan ini, diharapkan perpustakaan di era globalisasi tidak sekadar sebagai "kata benda", yaitu tempat menyimpan koleksi buku-buku dan aneka ragam koleksi lainnya, tetapi perpustakaan mampu bertransformasi sebagai "kata kerja" atau proses, yaitu tempat diseminasi dan persemaian ilmu pengetahuan.
\end{abstract}

Kata Kunci: Pustakawan, Globalisasi, Perpustakaan Digital, Digital Natives.

\title{
A. Pendahuluan
}

Berbicara mengenai peningkatan sumber daya manusia, sejatinya perpustakaan menempati peran yang sangat urgen. Hal ini selaras dengan pesan Undang-undang Nomor 43 Tahun 2007 Tentang Perpustakaan, terutama Pasal 3, yang menyatakan bahwa fungsi perpustakaan sebagai wahana pendidikan, penelitian, pelestarian, informasi, dan rekreasi untuk meningkatkan kecerdasan dan keberdayaan bangsa. ${ }^{1}$ Namun, apa yang kemudian

${ }^{1}$ Moh. Mursyid, Pustakawan dan Media Massa: dari Interaksi ke Dokumentasi (Yogyakarta: Ladang Kata, 2015), hlm. 49. 
terjadi, perpustakaan lebih banyak berfungsi sebagai tempat penyimpanan tumpukan buku-buku yang sepi dari kegiatan literasi, apalagi aktivitas penelitian dan pengembangan. Padahal, jika merunut sejarah, kemajuan Islam pada zaman Dinasti Abbasiyah bermula dan berpusat pada kegiatan ilmiah yang dilakukan di perpustakaan.

Pertanyaannya kemudian adalah kenapa peran perpustakaan yang demikian urgen dalam hal pengembangan sumber daya manusia serta pengembangan ilmu pengetahuan tidak terlaksana secara maksimal? Semuanya kembali kepada para pengelola perpustakaan itu sendiri. Hal ini diperkuat dengan penjelasan selanjutnya dalam Undang-undang Nomor 43 Tahun 2007 Tentang Perpustakaan, terutama Pasal 29, dan juga Pasal 1 ayat (8). Pasal 29 Undang-undang Nomor 43 Tahun 2007 Tentang Perpustakaan menyatakan bahwa tenaga perpustakaan terdiri atas pustakawan dan tenaga teknis perpustakaan. Pustakawan, sebagaimana penjelasan Pasal 1 ayat (8) Undang-undang Nomor 43 Tahun 2007 Tentang Perpustakaan, adalah seseorang yang memiliki kompetensi yang diperoleh melalui pendidikan dan/atau pelatihan kepustakawanan serta mempunyai tugas dan tanggung jawab untuk melaksanakan pengelolaan dan pelayanan perpustakaan. ${ }^{2}$

Dengan melihat fenomena dan kenyataan tersebut, maka menjadi langkah yang sangat diperlukan untuk merekonstruksi peran pustakawan. Dengan mengembalikan peran pustakawan ke tempat yang ideal, diharapkan aktivitas di perpustakaan tidak sekadar pada pinjam-meminjam buku, tetapi juga berkembang ke arah aktivitas literasi, penelitian, dan pengembangan ilmu pengetahuan. Melalui artikel ini, penulis akan mendedah peran pustakawan, terutama di era globalisasi, dalam rangka mengembangkan budaya literasi, lebih jauh lagi dalam rangka persiapan akreditasi perpustakaan.

\section{${ }^{2}$ Ibid.}




\section{B. Pembahasan}

\section{Beberapa Peran Pustakawan}

Sebagaimana diulas di atas, menurut Pasal 1 ayat (8) Undang-undang Nomor 43 Tahun 2007 Tentang Perpustakaan, tugas dan tanggung jawab seorang pustakawan adalah melaksanakan pengelolaan dan pelayanan perpustakaan. Kata "pengelolaan dan pelayanan perpustakaan" ini berdampak dan berimplikasi luas. Pengelolaan dan pelayanan perpustakaan seharusnya tidak berhenti pada melayani para users dalam meminjam buku. Pengelolaan dan pelayanan perpustakaan harus mengarah pada pengembangan budaya literasi dan pengembangan ilmu pengetahuan.

Salah satu peran pustakawan adalah menyelenggarakan pengelolaan dan pelayanan perpustakaan secara sistemik, bukan hanya menjalankan perpustakaan secara asal-asalan yang penting jalan. Dengan demikian, kerja dan tanggung jawab seorang pustakawan juga bersifat profesional, karena dilandasi oleh adanya suatu sistem yang baku dan berskala internasional. Implikasinya, seorang pustakawan harus bekerja secara profesional mengelola perpustakaan sesuai dengan sistem perpustakaan yang telah dibangun dan dikembangkan secara baku di dunia internasional. ${ }^{3}$ Tuntutan supaya pustakawan bekerja secara profesional ini lantas didukung dengan keluarnya Undang-undang Nomor 2 Tahun 1989 tentang Sistem Pendidikan Nasional yang mengakui pustakawan sebagai salah satu tenaga kependidikan. Undangundang ini kemudian diperkuat dengan terbitnya Keputusan Menteri Pendayagunaan Aparatur Negara Nomor 18 Tahun 1988. Dengan dua payung hukum inilah, pustakawan dituntut untuk bekerja lebih profesional dalam menyelenggarakan pengelolaan dan pelayanan perpustakaan. Dengan demikian, profesionalisme

3 A.C. Sungkana Hadi, "Peran dan Tanggung Jawab Profesional Pustakawan Sebagai Pengelola Sumber Informasi”, Jurnal Pustakawan Indonesia 4, No. 2 (2005), hlm. 15-16, http://jagb.journal.ipb.ac.id/index.php/jpi/article/ viewFile/2248/1268, diakses pada 15 November 2016. 
kepustakawanan berarti kemampuan, status, dan tanggung jawab untuk ikut berperan dalam meningkatkan pengetahuan dan kecerdasan masyarakat melalui pengelolaan dan penyediaan layanan informasi di perpustakaan, pusat dokumentasi, atau pusat informasi (pusdokinfo). ${ }^{4}$

Lebih lanjut Putu Laxman Pendit, sebagaimana dikutip oleh A.C. Sungkana Hadi, menjelaskan bahwa tugas dan fungsi pustakawan antara lain adalah mendukung dan memastikan kelancaran proses pembentukan pengetahuan lewat layananlayanan informasi yang diberikannya. Oleh karena itu, pustakawan harus mampu menentukan jenis-jenis informasiyangsesuaidengan kebutuhan penggunanya untuk meningkatkan pengetahuannya. Dengan kata lain, peran profesional pustakawan yang penting adalah sebagai penyaji informasi yang relevan dan berkualitas. Pustakawan harus mampu menyediakan fasilitas, suasana, dan sistem yang memungkinkan pencarian dan penemuan informasi yang relevan dan berkualitas di tengah banjir informasi yang semakin deras melanda para pengguna perpustakaan dan pencari informasi pada umumnya. ${ }^{5}$

Secara lebih luas, A. Ridwan Siregar memaparkan fungsi pustakawan lebih kepada fungsi manajerial. Di antaranya ada sembilan aspek manajemen yang mesti dijalankan oleh seorang pustakawan, yaitu:

a. Pengelolaan keuangan;

b. Pengembangan koleksi;

c. Pengorganisasian koleksi;

d. Pengaturan akomodasi;

e. Pembinaan staf;

f. Pelayanan teknis;

g. Pelayanan pengguna;

h. Peningkatan autamasi;

i. Perluasan kerja sama. ${ }^{6}$

${ }^{4}$ Ibid.

${ }^{5}$ Ibid., hlm. 16.

${ }^{6}$ A. Ridwan Siregar, "Peran Pustakawan dalam Pembinaan dan 
Secara ringkas, sebagaimana dijabarkan oleh A.C. Sungkana Hadi, peran pustakawan sebagai pengelola sumber informasi adalah:

a. Menyediakan dan mengembangkan koleksi sumber informasi yang relevan dengan kebutuhan pengguna, mutakhir, dan komprehensif. Oleh karena itu, pustakawan perlu memiliki kesiagaan informasi (information awareness), yakni kemauan untuk selalu berusaha memperoleh informasi yang mutakhir dan komprehensif, selalu mengikuti perkembangan penerbitan, termasuk untuk peningkatan pengetahuan dan kualitas diri sendiri.

b. Melakukan pengorganisasian koleksi sumber informasi berdasarkan sistem yang andal dan tepercaya, termasuk sistem yang berbasis teknologi informasi, agar setiap carik informasi di dalam koleksi tersebut dapat diketahui keberadaannya, dan dapat diketemukan dengan mudah, cepat, dan tepat.

c. Melakukan pemanduan bagi pengguna dalam menelusur dan/atau menjelajahi samudra informasi yang semakin luas, sehingga pengguna dapat memperoleh informasi yang sesuai dengan kebutuhannya (the right information for the right user).

d. Melakukan upaya-upaya promosi dan pembinaan minat baca masyarakat, agar melalui pemanfaatan intensif koleksi sumber informasi yang ada dapat dibangun dan dikembangkan suatu masyarakat yang gemar membaca dan gemar belajar (reading and learning society).

e. Melakukan upaya-upaya perekaman informasi dan pengetahuan lokal, termasuk upaya digitalisasi informasi, agar dapat diakses secara luas oleh masyarakat pengguna

Pengembangan Manajemen Perpustakaan Perguruan Tinggi dalam Era Globalisasi Informasi", hlm. 4-5, http://pustakaindonesia.org/wp-content/ uploads/2012/05/Peran-Pustakawan-dalam-Pembinaan-dan-PengembanganManajemen-Perpustakaan-Perguruan-Tinggi-dalam-Era-GlobalisasiInformasi.pdf, diakses pada 15 November 2015. 
tanpa batas ruang dan waktu. Oleh karena itu, pustakawan perlu siaga untuk berkembang menjadi pengelola ilmu pengetahuan (knowledge manager), bukan hanya pengelola buku, bukan pula hanya pengelola informasi. ${ }^{7}$

Itulah ulasan beberapa peran yang diemban dan harus dijalankan oleh seorang pustakawan. Melihat paparan di atas, tergambar dengan jelas bahwa seorang pustakawan tidak hanya secara teknis melayani para pengguna perpustakaan, bahkan tidak hanya merapikan buku-buku di perpustakaan. Seorang pustakawan secara lebih luas memiliki peran memberikan pendidikan literasi kepada para pengguna perpustakaan. Selain itu, peran pustakawan juga adalah sebagai seorang manajer yang mengelola dan merapikan aspek manajerial perpustakaan.

\section{Pustakawan dan Era Globalisasi}

Dalam Kamus Besar Bahasa Indonesia, definisi globalisasi adalah proses masuknya ke ruang lingkup dunia. ${ }^{8}$ Menurut Wikipedia, globalisasi adalah proses integrasi internasional yang terjadi karena pertukaran pandangan dunia, produk, pemikiran, dan aspek-aspek kebudayaan lainnya. Kemajuan infrastruktur transportasi dan telekomunikasi, termasuk kemunculan telegraf dan internet, merupakan faktor utama dalam globalisasi yang semakin mendorong saling ketergantungan (interdependensi) aktivitas ekonomi dan budaya. Sejumlah pihak berpendapat bahwa awal mula globalisasi terjadi di era modern. Namun, beberapa pakar lainnya menyatakan bahwa sejarah globalisasi bermula dari sebelum zaman penemuan Eropa dan pelayaran ke Dunia Baru. Ada pula pakar yang menyebut globalisasi terjadi pada milenium ketiga sebelum Masehi. Namun, fakta menunjukkan bahwa pada akhir abad ke-19 dan awal abad ke-20, keterhubungan ekonomi dan budaya dunia, yang menandai era globalisasi, berlangsung sangat cepat. Mulai pertengahan tahun 1980-an dan lebih sering

${ }^{7}$ Hadi, "Peran dan Tanggung Jawab Profesional Pustakawan Sebagai Pengelola Sumber Informasi”, hlm. 18.

${ }^{8}$ Kamus Besar Bahasa Indonesia, diakses pada 16 November 2016, http://kbbi.web.id/ globalisasi. 
lagi sejak pertengahan 1990-an, istilah dan frase globalisasi makin lagi sering digunakan. Pada tahun 2000, International Monetary Fund (IMF) mengidentifikasi empat aspek dasar globalisasi, yaitu perdagangan dan transaksi, pergerakan modal dan investasi, migrasi dan perpindahan manusia, dan pembebasan ilmu pengetahuan. Selain itu, tantangan-tantangan lingkungan seperti perubahan iklim, polusi air dan udara lintas perbatasan, dan pemancingan berlebihan dari lautan juga ada hubungannya dengan globalisasi. Proses globalisasi memengaruhi dan dipengaruhi oleh bisnis dan tata kerja, ekonomi, sumber daya sosial-budaya, dan lingkungan alam. ${ }^{9}$

Dalam menghadapi era globalisasi ini, setidaknya ada dua tantangan yang dihadapi oleh perpustakaan dan pustakawan. Pertama, pustakawan harus mampu menyelaraskan aneka koleksi yang ada di perpustakaan dengan perkembangan teknologi informasi. Kedua, pustakawan juga harus bisa menyelenggarakan layanan perpustakaan bagi generasi baru yang semakin familiar dengan penggunaan teknologi informasi, yang menuntut layanan yang serba cepat dan lebih bersikap aktif. Dalam istilah Oblinger dan Oblinger, sebagaimana dikutip oleh Kristina, generasi baru ini disebut digital natives. ${ }^{10}$ Lebih lanjut dijelaskan bahwa digital natives adalah seseorang yang dalam kehidupan sehari-harinya sering menggunakan teknologi informasi, dan mereka sudah mengenalnya sejak dini. Dengan demikian, mereka sangat terbiasa menggunakan bantuan teknologi informasi dalam kesehariannya, temasuk dalam akses informasi serta didukungnya era booming informasi seperti saat ini, di mana aksesnya sangat mudah. ${ }^{11}$

Menghadapi generasi digital natives ini, tentu perpustakaan, dan para pustakawan di dalamnya, tidak cukup

9 “Globalisasi”, diakses pada 16 November 2016, https://id.wikipedia. org/ wiki/Globalisasi.

${ }^{10}$ S. Kristina, “Transformasi Pustakawan dalam Era Globalisasi”, hlm. 1, diakses pada 15 November 2016, http://library.stiesia.ac.id/assets/lib-doc/ b4c693e2c92a6e49a45d5a98ede03808. pdf.

${ }^{11}$ Ibid., hlm. 1-2. 
menyediakan layanan perpustakaan yang konvensional. Dalam arti, perpustakaan hanya menyediakan koleksi berupa buku-buku dalam bentuk printed. Pustakawan harus mampu melengkapi koleksi dan layanan perpustakaan sesuai dengan tuntutan generasi digital natives dan tuntutan revolusi informasi yang semakin cepat dan melimpah ruah.

Sebagaimana dijabarkan oleh Kristina, dalam menghadapi tantangan era globalisasi ini, pustakawan harus mampu melengkapi perpustakaan dengan dua hal. Pertama, dari sisi penyediaan koleksi, perpustakaan tidak hanya dtuntut memiliki jenis koleksi buku teks yang lengkap saja, tetapi juga tersedianya jenis koleksi elektronik (e-books, e-journal, database online) serta audiovisual (berupa video). Kedua, dari sisi layanan, perpustakaan juga harus mampu menyediakan layanan yang bersifat one-stop service, adding value information and knowledge, dan kemudahan akses berbagai sumber informasi dan pengetahuan yang dimiliki dalam berbagai format. ${ }^{12}$

Secara sederhana, Diao Ai Lien membandingkan antara perpustakaan era lama dan perpustakaan era globalisasi dalam tabel berikut ini. ${ }^{13}$

Tabel 1

Perbandingan Perpustakaan Era Lama dan Era Globalisasi

Sebelum Internet Setelah Internet

Memberikan multi-entry service Menyediakan one-stop service: multiatau pelayanan yang terpisah untuk functional librarians serving multipengadaan, pengolahan, transaksi tasking customers.

peminjaman, referensi, dsb.

Mengumpulkan informasi dan Mengoleksi dan menyediakan akses pengetahuan secara likal, umumnya ke informasi dan pengetahuan serta dalam bentuk printed. sumber-sumbernya yang tersebar di seluruh dunia dalam multiformat.

Menjaga koleksi dan akses informasi Menambah nilai pada informasi dan dan pengetahuan. pengetahuan (adding value).
${ }^{12}$ Ibid., hlm. 2.
${ }^{13}$ Ibid., hlm. 2-3. 
Melayani individu atau kelompok Melayani individu atau kelompok tanpa melihat potensi hubungannya sebagai anggota jaringan.

dengan individu atau kelompok lain.

Memberikan pelayanan di tempat Memberikan pelayanan online selama dan terbatas pada jam pelayanan. 24 jam.

Manajemen informasi: memberikan Manajemen pengetahuan:memberikan pelayanan sebatas akses informasi pelayanan bervariasi dan dinamis, dan pengetahuan. meliputi seluruh siklus pengetahuan, mulai dari penciptaan, perekaman dan publikasi, penyebaran, penggunaan, dan penciptaan kembali pengetahuan.

Memberikan pendidikan pemakai Meningkatkan information skills and sebatas mengenai pemanfaatan literacy sedemikian rupa sehingga perpustakaan (library skills and pengguna dapat memanfaatkan literacy). teknologi informasi untuk mengakses dan memanfaatkan informasi secara kritis serta merekam dan mempublikasikan secara efisien.

Dari paparan di atas, penulis memberikan titik tekan terkait dengan peran pustakawan di era globalisasi pada empat hal. Pertama, pustakawan harus mampu mengoleksi dan menyediakan akses ke informasi dan pengetahuan serta sumber-sumbernya yang tersebar di seluruh dunia dalam multiformat. Dalam hal ini, bentuk koleksi dan layanan di perpustakaan bisa memanfaatkan perpustakaan raksasa di dunia maya yang tersedia dalam repository, e-book, e-journal, dan sebagainya. Dalam ranah ini, pustakawan bisa mengembangkan perpustakaan di era sebelum internet menjadi perpustakaan digital. Berbicara mengenai perpustakaan digital, Stevenson dan Collin, sebagaimana dikutip oleh Dio Eka Prayitno, menjelaskan bahwa perpustakaan digital merupakan tempat penyimpanan koleksi referensi digital seperti jurnal elektronik dan database informasi. Pada dasarnya, perpustakaan digital sama seperti perpustakaan konvensional. Hanya saja perpustakaan digital tempat penyimpanan informasi atau koleksi pustakanya tidak pada sebuah rak atau lemari, melainkan pada sebuah komputer atau server. ${ }^{14}$

${ }^{14}$ Dio Eka Prayitno, “Tantangan Membangun Perpustakaan Digital Perguruan Tinggi”, Prosiding Manajemen Perpustakaan Perguruan Tinggi untuk Net Generation: Tantangan dan Peluang, Universitas Muhammadiyah 
Kedua, tidak hanya menjaga koleksi dan akses informasi dan pengetahuan, pustakawan juga harus mampu menambah atau memberikan nilai pada informasi dan pengetahuan (adding value). Sebab, di era globalisasi dan percepatan informasi saat ini, hal yang terpenting bukan seberapa banyak menyerap dan mengumpulkan informasi, tetapi seberapa berbobot nilai (value) yang ditambahkan pada setiap informasi yang diperoleh, yang kemudian menjadi niai tambah bagi pengetahuan pengguna layanan perpustakaan.

Ketiga, tidak hanya memberikan pelayanan di tempat dan terbatas pada jam pelayanan, pustakawan di era globalisasi harus mampu memberikan pelayanan online selama 24 jam. Di sinilah perpustakaan modern di era globalisasi, lewat peran yang dimainkan oleh para pustakawan yang melek teknologi informasi, harus mampu membangun perpustakaan raksasa di dunia maya yang tersedia dalam repository, e-book, e-journal, dan sebagainya. Dengan demikian, para pengguna perpustakaan dapat memanfaatkan aneka kolehsi perpustakaan dalam bentuk repository, e-book, e-journal, dan sebagainya kapan pun dan di mana pun berada, bahkan hanya dari genggaman tangan dengan menggunakan perangkat gawai (gadget).

Keempat, jika sebelum era globalisasi peran pustakawan hanya sebatas pada manajemen informasi, yaitu memberikan pelayanan sebatas akses informasi dan pengetahuan, maka pada era globalisasi, peran pustakawan meluas pada manajemen pengetahuan, yaitu memberikan pelayanan bervariasi dan dinamis, meliputi seluruh siklus pengetahuan, mulai dari penciptaan, perekamandan publikasi, penyebaran, penggunaan, dan penciptaan kembali pengetahuan. Pada peran inilah seorang pustakawan juga harus menjalankan fungsinya pada pengembangan budaya literasi. Dalam hal ini, budaya literasi tidak berhenti pada budaya membaca saja, tetapi juga pada budaya berdiskusi, meneliti, dan

Jember, 7-8 November 2014, hlm. 167, http://eprints.perbanas.ac.id/226/1/ Tantangan $\% 20$ Membangun\%20Perpustakaan\%20Digital\%20Perguruan $\% 20$ Tinggi.pdf. 
menulis. Maka, pada titik inilah perpustakaan tidak hanya sebatas tempat menyimpan koleksi berupa buku-buku saja, melainkan juga sebagai tempat pengembangan ilmu pengetahuan.

Empat hal pokok inilah yang mesti dijalankan oleh para pustakawan dalam menghadapi era globalisasi. Dengan berjalannya empat fungsi ini, bisa dipastikan perpustakaan akan mengalami transformasi. Perpustakaan tidak hanya sebagai "kata benda", yaitu tempat menyimpan koleksi buku-buku dan aneka ragam koleksi lainnya, tetapi perpustakaan sebagai "kata kerja" atau proses, yaitu tempat diseminasi dan persemaian ilmu pengetahuan. Sebagai contoh adalah Perpustakaan Darul Hikmah pada masa keemasan Islam di zaman Dinasti Abbasiyah di era kepemimpinan Khalifah Harun ar-Rasyid. Pada zaman ini, Darul Hikmah sebagai perpustakaan resmi negara tidak hanya sebagai tempat menyimpan beraneka macam kitab-kitab karya para ulama, tetapi sebagai tempat berdiskusi, tempat belajar, tempat meneliti, dan tempat mengembangkan ilmu pengetahuan.

\section{Simpulan}

Peran pustakawan sangat urgen dalam peningkatan mutu dan kualitas sumber daya manusia. Peran tersebut semakin terasa di era globalisasi yang ditandai oleh revolusi dan banjir informasi yang sangat membludak. Di era percepatan dan banjir informasi ini, aktivitas di perpustakaan tidak sekadar pada pinjammeminjam buku, tetapi sebaiknya dikembangkan ke arah aktivitas literasi, penelitian, dan pengembangan ilmu pengetahuan. Di era globalisasi ini, ada empat peran penting pustakawan, yaitu mengoleksi dan menyediakan akses ke informasi dan pengetahuan serta sumber-sumbernya yang tersebar di seluruh dunia dalam multiformat, menambah atau memberikan nilai pada informasi dan pengetahuan (adding value), memberikan pelayanan online selama 24 jam, dan memberikan pelayanan bervariasi dan dinamis, meliputi seluruh siklus pengetahuan, mulai dari penciptaan, perekaman dan publikasi, penyebaran, penggunaan, dan penciptaan kembali pengetahuan. Dengan empat peran 
pustakawan ini, diharapkan perpustakaan di era globalisasi tidak sekadar sebagai "kata benda", yaitu tempat menyimpan koleksi buku-buku dan aneka ragam koleksi lainnya, tetapi perpustakaan mampu bertransformasi sebagai "kata kerja" atau proses, yaitu tempat diseminasi dan persemaian ilmu pengetahuan. 


\section{DAFTAR PUSTAKA}

“Globalisasi”, diakses pada 16 November 2016, https://id.wikipedia. org/wiki/ Globalisasi.

Hadi, A.C. Sungkana. "Peran dan Tanggung Jawab Profesional Pustakawan Sebagai Pengelola Sumber Informasi”, Jurnal Pustakawan Indonesia 4, No. 2 (2005), http://jagb.journal. ipb.ac.id/index.php/jpi/article/viewFile/ 2248/1268.

Kamus Besar Bahasa Indonesia, diakses pada 16 November 2016, http://kbbi.web.id/globalisasi.

Kristina, S. "Transformasi Pustakawan dalam Era Globalisasi", diakses pada 15 November 2016, http://library.stiesia.ac.id/ assets/lib-doc/b4c693e2c92 a6e49a45d5a98ede03808.pdf.

Mursyid, Moh. Pustakawan dan Media Massa: dari Interaksi ke Dokumentasi. Yogyakarta: Ladang Kata, 2015.

Prayitno, Dio Eka. “Tantangan Membangun Perpustakaan Digital Perguruan Tinggi", Prosiding Manajemen Perpustakaan Perguruan Tinggi untuk Net Generation: Tantangan dan Peluang, Universitas Muhammadiyah Jember, 7-8 November 2014, http://eprints.perbanas.ac.id/226/1/ Tantangan 20\% Membangun 20\% Perpustakaan 20\% Digital 20\% Perguruan 20\% Tinggi.pdf.

Siregar, A. Ridwan. "Peran Pustakawan dalam Pembinaan dan Pengembangan Manajemen Perpustakaan Perguruan Tinggi dalam Era Globalisasi Informasi”, diakses pada 15 November 2016, http://pustakaindonesia.org/ wp-content/ uploads/2012/05/Peran-Pustakawan-dalam-Pembinaandan-Pengembangan-Manajemen-PerpustakaanPerguruan-Tinggi-dalam-Era-Globalisasi-Informasi.pdf. 